\title{
AN AGRONOMIC EVALUATION OF SUBTERRANEAN CLOVER CULTIVARS
}

\author{
W. R. ScotT \\ Lincoln College, Canterbury
}

\begin{abstract}
Summary
The seasonal production of six cultivars of subterranean clover, Geraldton, Yarloop, Woogcnellup, Clare, Mount Barker and Tallarook, was evaluated under cutting in North Canterbury. Woogenellup and Clare produced more than $7,000 \mathrm{lb} \mathrm{DM} / \mathrm{a} \approx, 2,000 \mathrm{lb} \mathrm{DM} / \mathrm{ac}$ more than the other cultivars.. Geraldton produced the highest seed yield and seed yields tended to decline with increased lateness of flowering.
\end{abstract}

\section{INTRODUCTION}

LITrLe quantitative evidence on the performance of subterranean clover (Trifolium subterruneum L.) cultivars in New Zealand is available. Mt Barker and Tallarook are the only two used extensively, probably because seed is readily available (Saxby, 1956), although some Woogenellup is now being sown.

Smetham (1968) compared 18 cultivars of subterranean clover at three sites in Central Otago. On the basis of qualitative evidence, he concluded that as many as six cultivars including Woogenellup, Nangeela and Bacchus Marsh out-produced Mt Barker by $20 \%$ or more and he recommended the sowing of these three.

The aim of the present study was to provide some quantitative information on the performance in North Canterbury of several commercial cultivars including $\mathrm{Mt}$ Barker and Tallarook.

\section{EXPERIMENTAL}

Six cultivars, Geraldton, Yarloop, Woogenellup, Clare, Mt Barker and Tallarook, representing a wide range in flowering time, were selected for evaluation. All seed was of Australian origin and Government certified.

The trial site was approximately four miles north-east of Waikari at an altitude of $900 \mathrm{ft}$. This area has a reasonably well distributed mean annual rainfall of 30 in. but marked summer drought often occurs owing to the variability of the summer raill- 
fall together with the high evaporation prevalent over summt:r as a result of the prevailing north-east and north-west winc:s (Garnier, 1958). A total of 29 in. was recorded during 1968, the year in which the trial was conducted.

The soil type of the area is a Tipapa Hill Soil, pH 5.6, and the unimproved vegetation is dominated by danthonia (Notodanthonia spp.) along with hard tussock (Festuca novae-zelandiae) and silver tussock (Poa laevis) . During the 1967-8 summer, the area was cultivated and lime at $32 \mathrm{cwt} / \mathrm{ac}$ worked into the topsoil. The experiment was arranged as a randomized block with five replicaticns of the six cultivars, each plot measuring $6 \mathrm{ft}$ $\mathrm{x} 9 \mathrm{ft}$.

Inoculated seed of all cultivars was broadcast by hand at the rate of 45 viable seeds/sq. ft on March 2, 1968. After sowing, a basal application of $488 \mathrm{lb}$ of superphosphate and $2 \mathrm{oz}$ of ammonium molybdate was applied per acre. The plots were then lightly raked to just cover the seed.

Seedling counts taken on March 15, 1968, showed that there ' was considerable variation in density within each plot. Because of the significant influence of plant density on seed yield (Donald, 1954; Yates, 1961; Taylor and Rossiter, 1969) and to facilitate subsequent sampling for seed yield, two separate quadrats of 1 sq. $\mathrm{ft}$ in each plot were hand-thinned to a density of 24 plants per sq. ft. To eliminate "edge" effects around these areas, a border 6 in. wide was thinned to the same plant density and the area marked permanently.

Dry matter yields were determined by cutting to 1 in. from the soil with a surface Tarpen mower; A total of 3 cuts was taken outside the permanent quadrats. The first cut was on April 30 , the second on July 30 and the last on November 13 when all cultivars had begun to senesce. One of the two hand-thinned quadrats in each plot was also cut in April and July to examine the effect of cutting on seed production, Seed yields were determined by sampling the cut and uncut quadrats in each plot. All burrs were recovered by removing the top 2 in. of soil and separating out the burrs manually in the laboratory. The burrs were then counted and threshed and the seed cleaned and weighed.

\section{RESULTS AND DISCUSSION}

Treatment means and analysis of the April cut are shown in Table 1.

An analysis of covariance to remove "establishment" effects proved non-significant. Woogenellup, Clare and Mt Barker pro- 
TABLE 1: MEAN YIELDS APRIL CUT (lb DM/ac)

\begin{tabular}{lccc}
\hline \multicolumn{1}{c}{ Cultivar } & Sub. d over & Weeds & Total \\
\hline Geraldton & $219 \mathrm{~b}$ & $\mathbf{7 7} \mathrm{ab}$ & $\mathbf{2 9 6} \mathrm{b}$ \\
Yarloop & $\mathbf{2 8 2} \mathrm{b}$ & $48 \mathrm{~b}$ & $\mathbf{3 3 0} \mathrm{b}$ \\
Woogcnellup & $529 \mathrm{a}$ & $108 \mathrm{a}$ & $\mathbf{6 3 7} \mathrm{a}$ \\
Clare & $\mathbf{4 7 6} \mathrm{a}$ & $\mathbf{6 1} \mathrm{ab}$ & $\mathbf{5 3 7} \mathrm{a}$ \\
Mt Barker & $497 \mathrm{a}$ & $\mathbf{5 8} \mathrm{ab}$ & $\mathbf{5 5 5} \mathrm{a}$ \\
Tallarook & $239 \mathrm{~b}$ & $59 \mathrm{ab}$ & $298 \mathrm{~b}$ \\
S.E. Mean & $\pm \mathbf{4 2}$ & $\pm \mathbf{1 7}$ & $\pm \mathbf{4 2}$ \\
cv \% & $\mathbf{2 5}$ & $\mathbf{5 4}$ & $\mathbf{2 1}$ \\
\hline
\end{tabular}

Figures in a column sharing the same letter do not differ significantly at the $5 \%$ level of significance.

duced significantly more than the other cultivars. At this stage there was very little difference between cultivars in the amount of competition they were offering the weeds. The weeds consisted mainly of striated clover (Trifolium striatum), vulpia hair grass (Vulpia bromoides) and sheep's sorrel (Rumex acetosella) .

The results of the July cut which measured the regrowth following the April cut are presented in Table 2

TABLE 2: MEAN YIELDS JULY CUT (lb DM/ac)

\begin{tabular}{|c|c|c|c|}
\hline Cultivar & Sub. Clover & W eeds & Total \\
\hline Geraldton & $1,010 \mathrm{~cd}$ & $392 a$ & $1,402 \mathrm{ab}$ \\
\hline Yarloop & $1,218 \mathrm{bc}$ & $124 \mathrm{~b}$ & $1,342 \mathrm{ab}$ \\
\hline $\begin{array}{l}\text { Woogenellup } \\
\text { Clare }\end{array}$ & : 1,1,417 ab & 2631336 a & $1,6091,1,6001$ \\
\hline Mt Barker & $1,284 a b c$ & 324 a & $1,608 \mathrm{a}$ \\
\hline Tallarook & $893 \mathrm{~d}$ & $323 a$ & $1,216 \mathrm{~b}$ \\
\hline S.E. & \pm 93 & \pm 42 & \pm 105 \\
\hline $\mathrm{CV} \%$ & 17 & 37 & 16 \\
\hline
\end{tabular}

Figures in a column sharing the same letter do not differ significantly at the $5 \%$ level of significance.

There was no significant difference between the three highest yielding cultivars, Woogenellup, Clare and Mt Barker, which grew at the rate of about $15 \mathrm{lb} \mathrm{DM/ac/day} \mathrm{over} \mathrm{the} \mathrm{May-June-}$ July period. At Winchmore, Rickard (1968) found that ryegrasssubterranean clover (cv. Mt Barker) pastures produced at the rate of $8.4,5.0$ and $4.2 \mathrm{lb} \mathrm{DM/ac/day} \mathrm{for} \mathrm{May,} \mathrm{June} \mathrm{and} \mathrm{July,}$ respectively. The winter production at Waikari was therefore comparatively high, possibly because the trial area was situated on a sunny face which would have a better temperature and 
light regime than Winchmcre. The clover at the trial site showed little frost damage. High quality herbage such as this could play an important role in the provision of pre-lambing and lambing greenfeed during August, a critical month for feed supply (Stewart and Taylor, 1965).

At the July cut the two tallest cultivars, Yarloop and Clare, contained significantly fewer weeds than the more prostrate cultivars, Geraldton, Mt Barker and Tallarook. Woogenellup swards appeared to be intermediate in growth habit and weed content.

The results of the November cut are presented in Table 3.

TABLE 3: MEAN YIELDS NOVEMBER CUT (lb DM/ac)

\begin{tabular}{lcrc}
\hline \multicolumn{1}{c}{ Cultivar } & $\because$ - ‘Sub. Clover & Weeds & Total \\
\hline Geraldton & $1,462 \mathrm{c}$ & $2,644 \mathrm{a}$ & $4,106 \mathrm{~d}$ \\
Yarloop & $3,191 \mathrm{~b}$ & $1,578 \mathrm{~b}$ & $4,769 \mathrm{bcd}$ \\
Woogenellup & $5,154 \mathrm{a} \cdot:$ & $406 \mathrm{c}$ & $5,560 \mathrm{~b}$ \\
Clare & $5,938 \mathrm{a}$ & $632 \mathrm{c}$ & $6,570 \mathrm{a}$ \\
Mt Barker & $3,689 \mathrm{~b}$ & $874 \mathrm{c}$ & $4,563 \mathrm{~cd}$ \\
Tallarook & $3,348 \mathrm{~b}$ & $1,785 \mathrm{~b}$ & $5,133 \mathrm{bc}$ \\
S.E. & \pm 318 & \pm 191 & \pm 266 \\
cv $\%$ & 19 & 32 & 12
\end{tabular}

Figures in a column sharing the same letter do not differ significantly at the $5 \%$ level of significance.

Woogenellup and Clare produced significantly more than all other cultivars and these swards also contained. a low proportion of weeds.

In a self-regenerating annual such as subterranean clover, cultivar- recommendations cannot be based solely on dry matter production as continued production and persistence depends on a high seed yield. The approximate time of commencement of flowering for each cultivar together with the daily rainfall over the flowering and seed-setting period is presented in Fig. 1.

Approximately two months separated the time of flowering of Geraldton, the earliest flowering cultivar and Tallarook, the latest. Very little rain fell over the flowering period. As total seed yields are confounded by inherent differences in seed size between cultivars, both seed yields and seed numbers are prescinted in Table 4.

With the exception of Yarloop, there was 'a tendency for both seed yield and seed numbers to decline with increasing lateness of flowering. Although it appeared, that cutting increased the seed yield and seed number of all cultivars except Clare, this increase reached significance only in Geraldton. Cutting signiff- 
TABLE 4: THE EFFECTS OF CLJLTIVAR AND CUTTING ON TOTAL SEED YIELDS AND SEED NUMBERS

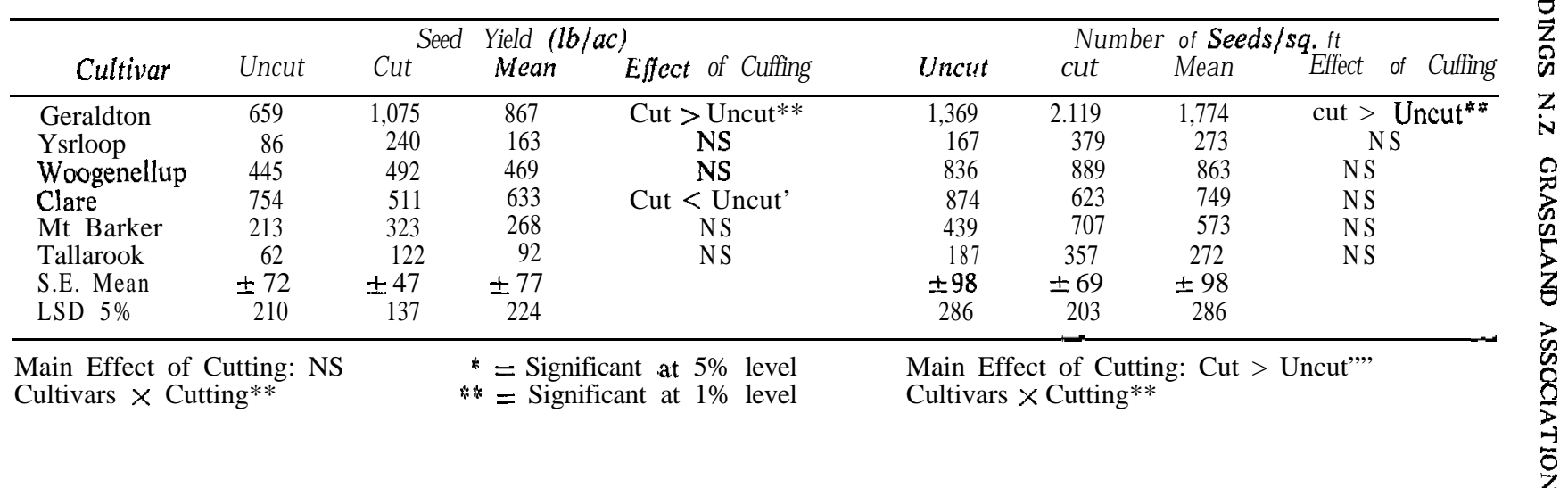


cantly reduced seed yield of Clare, an aspect which obviously needs closer examination before this high yielding cultivar can be widely recommended for use under grazing.

Rossiter (1966) has postulated that a subterranean clove1 cultivar can only be successful in a Mediterranean environment when it can produce about $500 \mathrm{lb} / \mathrm{ac}$ of seed in pure swards. At Waikari the only cultivars to achieve this "threshold" seed yield were Geraldton and Clare with Wogenellup slightly below.

In extrapolating the results of this trial to cultivar recommendations, three limitations should be kept in mind:

(1) The trial was carried out for only one year.

(2) The trial site was located on a sunny face.

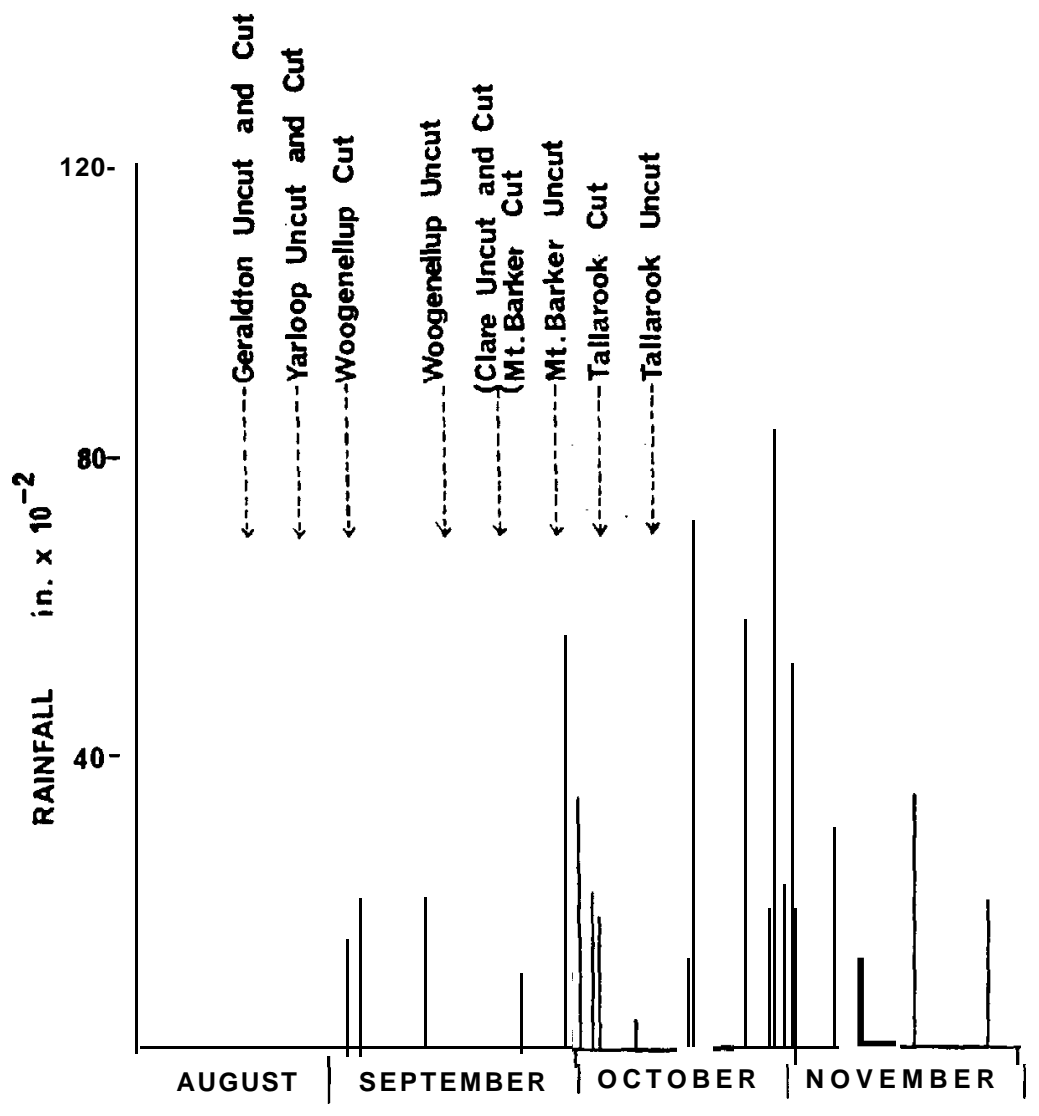

Fig. 1: Time of flow ering and rainfall. 
(3) Cultivar:behaviour under grazing may.differ from that under

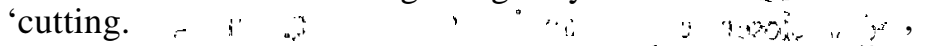
Subject to these limitations, it is suggested that Woogenellup, and perhaps Clare, could well replace, Mt: Barker"and Tallarook in many areas with. a climate similar to that of, Waikari-Both Woogenellup and Clare produced significantlymore herbage than the other "cultivars and also produced: satisfactory seed. yields despite the dry season experienced. [However, these two cuiltivars may not be the most suitable for every district of: New Zealand as other work has demonstrated ' (Scott,it.1971): Only further long-term trials will determine the most suitable cultivar for each district.

$$
\text { ACKNOWLEDGEMENTS " w }
$$

I thank Professor R. H. M. Langer, Plant Science Department, Lincoln College, for his helpful supervision and advice and my colleagues in the Plant Science Department for constructive criticism of the manuscript.

\section{RËFERENCES}

Donald, C. M., 1954: Aust. J. agric. Res., 5: 585-97.:"

Garnier, B. J., 1958: The Climate of Nêww Zealand. Édward Arnold, London, $191 \mathrm{pp}$.

Rickard, D. S., 1968: Proc. N.Z. Grassld A SS., 30: 81-93.

Rossiter, R. C., 1966: Aust J. agric. Rés., 17: 425-46..

Saxby, S. H., 1956: N.Z: Jl Agric., 92: 518-27.

Scott, W. R., 1971: Aust. J. exp. A gric. Anim. Husb., 11; 202-6.

Smetham, M. L., 1968: Proc. N.Z. Grassld Ass., 30: 114-21.

Stewart, J. D.; Taylor, N. W., 1965: Proc. 15th Lincoln Coll. Fmrs' Conf.: 93-9.

Taylor, G. B.; Rossiter, R. C., 1969: Aust. J. exp., Agric. Anim. Husb., 9:' 92-8.

Yates, J. J., 1961: Aust. J. agric. Res., 12: 10-26.

\section{DISCUSSION}

Cullen (Invermay) asked if it might be possible to obtain similar results with mixtures of subterranean clover with other legumes and grasses. Scott thought that the problem would be to find a legume, apart from lucerne and sub. clover, which would persist. Competition would probably be similar to 'that with weeds - i.e., taller cultivars would compete better with grasses than the lower growing ones. Mitchell (Palmerston North) commented that no mention had been made of oestrogen effects but Scott stated that there. was little trouble from this in. Canterbury little flushing of ewes was "carried out on sub. clover. Phosphate level was also connected with oestrogen level. Bennett (Christchurch) asked whether the seed was inoculated and, if so, whetherr the appropriate strains were used. Scott replied that all cultivars were inoculated with effective strains and all plants were obvicusly well nodulated. In some areas. poor reestablishment was not altogether a lack of nodulation but one of availability of seed, because much might germinate in a wet summer spell and then be wiped out by. a period of drought; 